Stoa

Vol. 10, no. 19, 2019, pp. 86-97

ISSN 2007-1868

\title{
JOSÉ BENIGNO ZILLI: PRESBÍTERO, FILÓSOFO, COMUNICADOR E HISTORIADOR
}

José Benigno Zilli: Presbyter, Philosopher and Historian

"Maestro te llamaban tus amigos"

JACOB BUGANZA

Instituto de Filosofía, Universidad Veracruzana

MARIO CERDÁN

Facultad de Filosofía, Universidad Veracruzana

\section{Introducción}

Escribir en torno a la figura de un personaje como el que en esta ocasión nos ocupa, y ante el cual nuestro afecto podría tildarse de "sumo", resulta una tarea que objetivamente impone dos retos. Por un lado, sintetizar y exponer una larga, pletórica y multifacética vida, la cual ciertamente nunca estuvo detenida, a pesar de la enfermedad. Toda vida se desarrolla en múltiples espacios, y esto la vuelve compleja de analizar. En el caso de Zilli, baste citar algunos sitios por los que transita y se le recuerda: la universidad (la Universidad Veracruzana, fundamentalmente), los medios de comunicación y, ante todo, la pastoral de la Iglesia. Por otro lado, presentar de manera sucinta y clara un compendio de su obra, supone discriminar algunos datos y detalles en favor de otros. No obstante, y a pesar de los dos retos objetivos y el afecto subjetivo, presentaremos brevemente los que consideramos más relevantes en los ámbitos biográfico, histórico y filosófico, con el fin de conmemorar el primer aniversario luctuoso de José Benigno Zilli Mánica. 


\section{Esbozo biográfico y la tesis doctoral en filosofía}

Nace José Benigno en Tepatlaxco, municipio ubicado al centro del estado de Veracruz, el 30 de junio de 1934. Fue trasladado, en la infancia, junto con su familia, a Loma Bonita, Oaxaca, y luego también a la Colonia Manuel González, perteneciente a la municipalidad de Zentla, nuevamente en el estado de Veracruz. Vive el vaivén que tenían aquellos descendientes de los migrantes italianos que llegaron a México a finales del siglo XIX y principios del $\mathrm{XX}$, cuya finalidad fue generar nuevas condiciones de vida, trabajando y conquistando un patrimonio propio (en Italia algunas de estas familias no habían logrado consolidarlo, debido a factores diversos que no es posible reproducir aquí). La itinerancia en sus primeros años fue un distintivo, y recuerda las constantes migraciones de un pueblo como el italiano, sometido a los cambios constantes. El aspecto de su origen italiano es un tema al que Zilli dedica buena parte de sus investigaciones de madurez, y es frecuentemente recordado por sus publicaciones en torno a él.

Educado por sus padres José Zilli y Teresa Mánica, junto con sus hermanos Carlos, Alfredo y Estela, fue muy cercano, como era natural, a sus abuelos Juan Zilli, Rosa Bernardi, Antonio Mánica y María Toss, en un contexto provinciano, de hibridez entre lo italiano y lo mexicano. Un ambiente pío, pero no puritano, comunitario, pero no masificador. Sus primeras letras las cursa en una primaria de Loma Bonita, y es en estos años en que decide ingresar a la Escuela Apostólica ubicada en la región de Xalapa. Así inicia una formación en humanidades que lo conducirían al futuro ministerio presbiteral. Fue su decisión, aunque durante dichos años seguía a uno de sus hermanos que buscaba la misma consagración. Finalmente el hermano desiste, mas el joven Benigno Zilli persevera.

En este contexto formativo surge la oportunidad para continuar su formación académica y eclesiástica en Europa. El viaje y estancia en el Viejo continente le llevan a la España franquista, a la Italia y Alemania de la posguerra. Esta larga travesía por Europa está marcada por un enorme crecimiento cultural y humanístico, que le permite continuar lo que sería la Bildung de sí mismo, su autoformación, y que le otorga una visión cosmopolita y, sobre todo, un compromiso social hacia México. Durante la década en Europa puede forjar un carácter disciplinado y alegre, amable y de probidad, que le acompañarían hasta el final de sus días. Conocer de cerca las carencias mexicanas y la vida en ultramar le posibilita superar la tentación del clericalismo. Abo- 
ga en muchas ocasiones por una promoción digna de la Doctrina Social de la Iglesia y, sobre todo, por su aplicación realista y urgente. Sobre su propia biografía, baste recordar la manera en que él mismo se reseña en su temprana tesis doctoral, y cómo es que se refiere a su paso formativo por Europa: "Estudió" Filosofía y Teología en la Universidad Gregoriana de Roma y allí consiguió la licencia en Filosofía. Estudió la lengua alemana en el Goethe Institut de Brilon en Westf. En la Universidad de Bonn (Alemania Occidental) asistió a las clases de los profesores: Rüfner, Jedin, Meurers, Perpeet, Barion, Maurer, etc." ${ }^{1}$ Sin duda, su mayor trabajo de investigación en el campo de la filosofía, por su erudición y calidad, fue la tesis para obtener el grado de Doctor en Filosofía en la Rheinische Friedrich Wilhelms-Universität, en Bonn, cuyo título es Introducción a la psicología de los conimbricenses y su influjo en el sistema cartesiano. En este texto, Zilli efectúa un rastreo de la escuela de Coimbra, que regenteaba la Compañía de Jesús en Portugal, en el lejano siglo XVI. Es justamente en Coimbra donde se gestan una serie de Comentarios (lectio et commentarium) en torno a la cuestión del alma; además, como da cuenta el texto de Zilli, la escuela conimbricense recurre a la física y la metafísica de Aristóteles y Tomás de Aquino para explicar la vida humana.

No está de más recordar que el Aquinate, para este tiempo, seguía siendo sumamente debatido, es decir, no eran aceptadas y comprendidas sus tesis del todo; tuvieron que pasar muchos años para ser asimilado y depurado el aristotelismo que aún llevaba un tinte de averroísmo. De Coimbra a La Fléche (donde se educa Descartes) existía por aquel tiempo un nexo por los profesores y, sobre todo, por los manuales, que eran compartidos. Precisamente Descartes, reconocido como el célebre "padre de la filosofía moderna", rebate algunos aspectos teóricos y conceptuales que se vinculaban a La Fléche, y por extensión a Coimbra. Dicho en otras palabras, la modernidad cartesiana busca unas certidumbres inamovibles que se deben alejar de las inseguridades que se plasman en los comentarios de las ideas de los conimbricenses, porque resultan todavía muy "especulativos". A partir de este esbozo, puede vislumbrarse la importancia de la tesis doctoral de Zilli, pues "muestra que los sistemas filosóficos han de ser estudiados no sólo especulativamente y tal como se encuentran, sino también históricamente y según se fueron desarrollando y que con ello se puede llegar a una más profunda inteligencia de los mismos". ${ }^{2}$ Es-

1 Zilli Mánica, J. B., Introducción a la psicología de los conimbricenses y su influjo en el sistema cartesiano, Editora Xalapeña, Xalapa, 1960 , p. 103.

${ }^{2}$ Ibídem, p. 9 
ta perspectiva metodológica permite ver la cercanía que tiene Zilli en su tesis doctoral con las tesis fundamentales de la hermenéutica filosófica del siglo $\mathrm{XX}$.

En suma, los resultados a los que llega Zilli son los siguientes. Primero, para que Descartes pudiese llegar a plantear sus revolucionarias tesis, hay que recordar que fue educado en La Fléche durante nueve años, y que conoce la filosofía que se enseñaba en el ambiente escolástico. A ella se dirige su refutación, incluso sin dejar de usar el lenguaje escolástico, aunque lo hace con imprimiendo a los términos originales nuevos matices. Aun con todo, efectivamente la filosofía de Descartes no fue completamente nueva o radical, por decirlo de un modo, pues recobra elementos que ya la tradición había trabajado a lo largo del Medievo. En efecto, hay muchas reminiscencias de san Agustín en el planteamiento de Descartes, como se aprecia en aquella voz de la consciencia o del yo. Lo que hay que recalcar es el carácter fundante que René Descartes quiere dar a su filosofía y, por ende, su forma de establecer el orden para conocer al mundo y la vía privilegiada del sujeto. Esto impacta irremediablemente al estatus de la filosofía, que pasa de ser una mera ancilla Theologiae pueden estar en tela de juicio por ningún motivo.

En segundo lugar, el filósofo de Tepatlaxco muestra cómo la línea de causalidades tiene su origen en el antiguo y célebre De Anima de Aristóteles, pues de él emanan las disquisiciones y consideraciones de la psicología filosófica de su tiempo. El alma actúa como principium operationum en la filosofía de Aristóteles, y los escolásticos añaden, siguiendo al Aquinate, que el alma intelectiva apetece al cuerpo (este movimiento sólo puede darse mediante una búsqueda racional de iure, no de facto); por tanto, sostienen que es la unión substancial la que compone al hombre. Mas Descartes agudiza el papel del unum substantiale en favor de su dualismo. Los argumentos de Coímbra, que el propio Descartes conoce de primera mano, le resultan inaptos para sus propósitos. Por ello Zilli concluye: "De esta metodología proviene el que aún con los mismos nombres Descartes quiere significar cosas diversas de los escolásticos. Para Descartes el alma intelectiva no es un espíritu esencialmente ordenado a informar el cuerpo, sino toda su esencia está contenida en el ámbito de pensar"3. Repetitio mater studiorum est: el alma, que en la tradición fue vista como unidad simple, inmortal, como espíritu ordenado a informar al cuerpo, se transmuta para delimitarse a las tareas de la res cogitans, distinguiéndola de su contraparte, la res extensa. Por ello René Descartes escribe,

3 Ibídem, p. 62 
en su IV meditatio: "Quia ex una parte claram et distinctam habeo ideam mei ipsius quatenus sum res cogitans, non extensa; et ex alia parte distinctam ideam corporis, quatenus est tantum (res) extensa non cogitans, certum est me a corpore meo revera distinctum et absque illo posse existere" ${ }^{\text {. }}$. Esto último se interconecta con los comentarios de Coímbra: "Credunt animan separatam nulla habita ratione gloriae vel damnationis, sed in statu separationis, ut nunc loquimur, minime desideranturam (si recte sapiat) reunionem ad corpus" $"$. Ambos textos ilustran la cercanía e influjo de sentido que tuvo Coímbra para la gestación del pensamiento cartesiano, tesis que sustenta justamente Zilli en su trabajo.

En tercer lugar, de su tesis puede rescatarse también la metodología filosófica que tiene por meta no contentarse por las apariencias, por las superficialidades, sino que intenta ir a lo fundamental, a la raíz. Por ello, en ocasión de su jubilación de las Universidad Veracruzana, Zilli dice certeramente:

Siempre he tenido la idea de que la Filosofía va a la raíz, y que más allá de lo descubierto, o demostrado, se adentra en el mundo de lo no conocido, que crece a medida que crecen los conocimientos. Se trata del ejercicio o disciplina de la razón hasta sus últimas consecuencias que puede incluir que nada tenga sentido o que todo sea fruto del azar o las circunstancias. La pluralidad de las teorías que se proponen, o los diversos modos de ver o interpretar el mundo y la vida del hombre tienden a hacer más radical la duda y a desembocar en el escepticismo y la indiferencia. Pero, por mi parte, he tenido siempre en la mente que la realidad que vemos no es la primera ni la originaria, por más que carezca de grandeza e inteligibilidad [... ] La realidad primera, por su parte, se presenta como un verdadero misterio y un interrogante. De metafísica están hechos todos los días de nuestra vida ${ }^{6}$.

Durante el periplo de diez años por Europa, también asiste a cursos y a conferencias de Joseph Ratzinger, José Vasconcelos, Gabriel Marcel, y muchos otros pensadores. En México siempre goza de la amistad de muchos contemporáneos, como Sergio Pitol, y de sus propios alumnos, que se cuentan por varios, y que sobrepasan las aulas de Humanidades. Igualmente, y a lo largo de los años, continúa su formación dialogando en México con José Gaos, Adolfo Sánchez Vázquez, Fernando Salmerón, Luis Villoro, Walter Redmond

\footnotetext{
${ }^{4}$ Ibídem, p. 60

${ }^{5}$ Ibídem, p.60

${ }^{6}$ Filosofía día a día.Discurso de jubilación de la Facultad de Filosofía de la Universidad Veracruzana, José Benigno Zilli Mánica (2003) consultado el 10 de julio del 2017. http:/ /www.jbzilli.com/2013/02/filosofía-día-día.html?q̄iscurso
} 
y Mauricio Beuchot, entre muchos más. Por más de cincuenta años, con breves intervalos fuera, radica en Xalapa, la que consideraba su ciudad, y la cual, en retribución, le otorga una medalla al mérito ciudadano en 2013.

En el campo docente, Zilli desarrolla su trabajo fundamentalmente en dos lugares, a saber, en la Universidad Veracruzana y en el Seminario Arquidiocesano de Xalapa. En la Universidad Veracruzana, luego de ser invitado por Fernando Salmerón para que se integre a la plantilla docente en 1966, fue $a b$ initio profesor por horas. Después obtiene la condición de Profesor de tiempo completo; llega a ser Director de la Facultad de Filosofía en 1989, de manera interina, y luego de 1990 a 1994 ya como titular. Un año después, en 1995, funda la Maestría en filosofía, de la que fue su primer coordinador hasta el momento de su jubilación, acaecida en 1997. En el Seminario Arquidiocesano de Xalapa, fue profesor de materias diversas (de biología, incluso), desde los años sesenta. Más adelante, y buscando consolidar los estudios de filosofía, funda y dirige la Facultad de Filosofía "Rafael Guízar y Valencia" del Seminario Mayor, a principios del año 2000. Se retira definitivamente de la actividad docente formal en 2013. Alternando las actividades de su condición de clérigo, académico, comunicador e investigador, Zilli concluye varios proyectos académicos, entre los que destaca su aportación a la historiagrafía regional, concretamente a la inmigración italiana en México.

\section{Bibliografía de José Benigno Zilli}

Durante sus años de docencia, Zilli ejercita una manera especial para perdurar e impactar en los otros, a saber, el periodismo. Con incursiones en rotativos como la sección dominical Concilio del Diario de Xalapa, Punto y aparte, Excélsior, El Dictamen, Política, Alégrate; pero también desenvuelve su escritura en revistas especializadas y de divulgación como lo son La palabra y el Hombre, Analogía, Anuario, Literal, Ulúa, entre otras. Pero son sus obras de investigación las que le permiten mantenerse presente en el ámbito académico, más allá del personal, en el que siempre estará en la memoria de quienes le conocieron. El eje principal de su investigación académica lo constituye la investigación sobre la migración italiana en México hacia finales de los siglos XIX y principios del XX. Ciertamente, este aporte historiográfico lo enorgullecía en vida, y le vale una pléyade de reconocimientos, sobre todo del gobierno de la República de Italia. En efecto, estos trabajos le valieron el reconocimiento de la población descendiente de los italianos que llegaron a México en busca de una mejora en su vida. Pero también otros académicos 
(no necesariamente itálicos) reconocieron la altura intelectual de Zilli, y el gran bien que había aportado a la Universidad Veracruzana ${ }^{7}$.

Las obras que giran sobre el eje de las investigaciones sobre la migración italiana son: Italianos en México, Ediciones San José, Xalapa, 1981, 515 páginas;Braceros italianos para México, La historia olvidada de la huelga de 1900, Universidad Veracruzana, Xalapa, 1986, 93 páginas; ;Llegan los colonos! Prensa de Italia y de México sobre la migración del siglo XIX, Ediciones Punto y Aparte, Xalapa, Ver, 1989, 338 páginas; La Villa Luisa de los italianos, Un proyecto liberal, Universidad Veracruzana, Xalapa, 1997, 142 páginas; La Estanzuela, Historia de una cooperativa agrícola de italianos en México, Editora del Gobierno del Estado de Veracruz-Llave, Xalapa, 1998, 148 páginas. Además de esta obra en solitario, Zilli llevó a término varios libros más sobre la migración italiana junto a Renzo Tommasi, de la Universidad de Trento. Estos libros son los siguientes: Tierra y libertad: l'emigrazione tretina in Messico, Giunta della Provincia Autonoma di Trento, Trento, 2001, 263 páginas; La colonizzazione italiana in Messico, la Cooperativa di emigrazione agrícola trentina "S. Cristoforo" (1921-1925), La colonización italiana en México. Giunta della Provincia Autonoma di Trento, 2005, 358 pp; Messico La tierra prometida. La Colonia italiana “Díez Guitérrez" trentino tirolese (1882), Giunta della Provincia Autonoma di Trento, Trento, 2007, 297 páginas.

Pero hay otros textos de Zilli sobre temas diversos, sobre todo de filosofía. En ellos se exponen notas ensayísticas, emanadas del día a día surgidas de las reflexiones en las aulas y en el caminar por la ciudad. Comentarios que surgen de las preocupaciones de nuestro autor. Algunas fueron pronunciadas en la Radio, pues no hay que olvidar sus participaciones en Grupo Avanradio, desde Xalapa. Por este medio se hizo más popular, incluso para personas alejadas de los ámbitos académico y eclesiástico. Los libros en donde se compilan estos trabajos son: Día y hora, Ediciones San José, Xalapa, 1980, 176 páginas; Radar, Ediciones Punto y Aparte, Xalapa, 1987, 196 páginas; Frailes Curas y Laicos, Colección V Centenario, Xalapa, 1991, 138 páginas; De

\footnotetext{
${ }^{7}$ Miembro de la Academia Mexicana de la Educación A. C. (1983); Miembro de la Orden al Mérito de la República Italiana con el grado de "Cavaliere" (1986); Miembro de la Comisión Estatal Conmemorativa del V Centenario del Encuentro de Dos Mundos; Presidente de la Comisión para la Protección y Difusión de nuestro patrimonio arquelógico, histórico y artístico (1990); galardonado a la presea "Benito Juárez", en el Congreso del Estado de Veracruz, otorgado por el Movimiento Ciudadano (2013); gozó de otros reconocimientos por su labor, como hijo predilecto de esta región veracruzana. Incluso en Huatusco, Veracruz, tiene un busto en su honor y el museo de la colonia Manuel González lleva su nombre.
} 
la Tarea Académica, Editora del Gobierno del Estado de Veracruz-Llave, Xalapa, 1994, 403 páginas; Amado amante, Crónica del Banquete de Platón, Editora del Gobierno del Estado de Veracruz-Llave, Xalapa, 1996, 149 páginas; Comentarios. Acotaciones marginales, Editora de Gobierno del Estado de Veracruz-Llave, Xalapa, 1996, 163 páginas; Cuentos en un caracol, Durandarte Editores, Xalapa, 2003, 70 páginas.

\section{Sobre el problema de la verdad}

En el ámbito de la filosofía, además de La psicología de los conimbricenses y su influjo en el sistema cartesiano, como dijimos publica De la tarea académica, que compila varios trabajos de distintas dimensiones, en un solo volumen, brindan al lector una idea de los caminos que ha seguido en su filosofar. Resulta más sobresaliente De la tarea académica en relación a los otros dos libros estrictamente filosóficos, a saber, Comentarios. Acotaciones marginales, que compila pequeñas cápsulas filosóficas y teológicas sobre asuntos varios, muchos de ellos publicados en diarios veracruzanos; y Amado amante. Crítica del Banquete de Platón, en donde hace gala de su dominio de la filosofía griega. En este apartado sólo abordaremos la temática áspera y espinosa sobre la verdad, y no de una sola, sino de la teoría metafísica de la misma, que se halla in nuce en el pensamiento de Zilli, plasmado concretamente en De la tarea académica.

Lo primero que debe decirse es que Zilli se sirve de un modelo analítico para llevar a cabo su reflexión. Utiliza, para su fin, lo que Morris había utilizado para la semiótica o estudio de los signos. Nos parece que es muy adecuada una caracterización de la verdad en tal dirección, pues no descarta ninguna de sus posibles ramificaciones. Es por eso que Zilli asegura que la pregunta por la verdad implica varias cosas: "punto 1) La cuestión teórica o definicional del predicado 'es verdad'; punto 2) La criteriología para conocer cuándo una proposición o sistema pueden tenerse legítimamente por verdaderos; punto 3) La aplicación concreta de los criterios a un caso particular, que suele ser el pan nuestro de cada día"

La primera parte de la tesis es que la verdad es una propiedad de las proposiciones o enunciados. Esto viene ya desde Aristóteles, pues dice que la verdad no es algo de las cosas, sino de la inteligencia que juzga ( $\alpha \lambda \lambda \varepsilon \nu \delta \iota \alpha \nu \circ\llcorner\alpha)^{9}$.

\footnotetext{
${ }^{8}$ Zilli, José Benigno,De la tarea académica, Gobierno del Estado de Veracruz-Llave, Xalapa, 1994, p. 38

${ }^{9}$ Cfr. Aristótles, Metafísica VI, 4
} 
Nos parece una grave omisión por parte de Fernando Salmerón cuando dice (dialogando con Heidegger) que "(El) concepto tradicional que ve en el juicio el lugar original de la verdad, además de que nunca fue defendido por Aristóteles $[\ldots]^{\prime 10}$, cuando es, por el contrario, uno de sus principales defensores. Que sea o no algo que apoye Heidegger, es cosa distinta. Mas era necesaria esta puntualización, a pesar de que reconocemos en Salmerón un extraordinario maestro.

Ahora bien, los enunciados pueden ser sólo una oración, o bien un sistema completo y acabado de oraciones. ¿Cómo decir si son ellos verdad o no? Siguiendo a Zilli, se puede decir que hay tres ramificaciones de la verdad, pero íntimamente compenetradas; en otros términos, no son independientes, sino que se complementan. La primera es la verdad sintáctica o de coherencia: "Todo enunciado depende en realidad de otros enunciados y de las relaciones lógicas que mantiene con ellos"11. Es importante recalcar la palabra "lógica", como lo hace Zilli, pues lógico es un cuento, una historia o una fantasía. Si nos quedamos sólo con esta faceta de la verdad, empobreceríamos mucho su concepto, pues equivale simplemente a poseer "consistencia". Beuchot la resume así: "Basta con que se guarde consistencia interna de las proposiciones y del sistema de proposiciones en sí, para que se tenga la verdad" ${ }^{2}$. Los cuentos de Tolkien o Lovecraft, por ejemplo, mantienen una consistencia o coherencia internas tales que son verdaderos sintácticamente hablando, pero no van más allá de este tipo o ramificación de la verdad.

Desde nuestra perspectiva, la pragmática debe estar subordinada a la semántica, por lo que explicaremos primero en qué consiste aquélla. La teoría de la pragmática ha sido impulsada por el segundo Wittgenstein, quien en sus Investigaciones filosóficas propone que el uso de las palabras, y la verdad de las mismas, viene dada por el contexto en que se encuentra el usuario. Por ejemplo, en una construcción, los trabajadores se encuentran justamente en lo suyo. Uno de ellos grita a otro "imartillo!". Bien podría ser que su apodo sea martillo, pero lo que quiere significar, en su contexto, parece más bien el imperativo de que algún otro le pase un martillo para trabajar, aunque bien es cierto que podría significar otras cosas, como el hecho de que un martillo esté cayendo desde lo alto de la construcción. Así es que "el predicado "es

${ }^{10}$ Salmerón, Fernando, Ensayos de filosofía moderna y contemporánea, UNAM, México, 2001, p. 101.

${ }^{11}$ Zilli, José Benigno, De la tarea académica, op. cit., p. 39

${ }^{12}$ Beuchot, Mauricio, "Sobre algunos aspectos del filosofar de José Benigno Zilli Mánica", en: Punto y Aparte, 10/04/2003, Xalapa, p. 10 
verdadero' no es un predicado de las proposiciones, sino del uso que se haga de ellas"13. Es lo que han seguido muy de cerca Peirce, Strawson, Dummet, Habermas y $\mathrm{Apel}^{14}$. Mas la pragmática requiere de algo más que de la sola sintaxis.

El elemento faltante parece ser la semántica, a saber, la correspondencia con la realidad. Es una actualización de aquella vieja tesis aristotélica que dice la verdad consiste en decir lo que una cosa es cuando es. Ciertamente ha sido una noción de verdad recogida desde la Antigüedad y la escolástica. Es la verdad como adecuación o correspondencia con la realidad. Es necesario recobrar esta noción porque, cuando hablamos, no lo hacemos para quedarnos en el puro sentido, sino que buscamos la referencia, la realidad a la que se apunta. El conocimiento y el lenguaje, por ello, son intencionales. Esta verdad semántica se puede dividir tanto en especulativa o teórica como en práctica. Dice Manuel Ocampo: "La verdad especulativa consiste en la adecuación del contenido del entendimiento con la cosa tal como es en sí misma; mientras que la verdad del entendimiento práctico consiste en la adecuación del artefacto que se está produciendo con el contenido del entendimiento práctico" ${ }^{15}$. La primera es la verdad lógica, la que encarna la antonomasia en la semántica; la segunda es poder plasmar la idea que se tiene en la mente en el artefacto, es decir, en lo fabricado.

Creemos que un cuadro completo de la teoría de la verdad debe incluir los tres elementos antes descritos. Zilli lo hace de una manera muy correcta y clara. Pensamos que en la filosofía todavía hace falta integrarlas de manera eficiente, cosa que pareciera hacer Mauricio Beuchot, recuperando un aristotelismo perenne y actualizándolo con las nuevas aportaciones a través de la hermenéutica.

\section{Conclusión}

Zilli es, para todo aquel que lo haya leído y escuchado, talento a la hora de escribir y hablar. Se puede decir que su estilo es único y envidiable, incluso entre los filósofos y los más doctos. Tiene la muy estimable característica de ser un pensador que plasma sus ideas de una manera clara y sencilla,

\footnotetext{
${ }^{13}$ Zilli, José Benigno, De la tarea académica, op. cit. p. 42

${ }^{14}$ Beuchot, Mauricio, Sobre el realismo y la verdad en el camino de la analogicidad, Universidad Pontificia de México, México, 1998, p. 6.

${ }^{15}$ Ocampo, Manuel, La verdad, su valor y su conocimiento, Universidad Anáhuac del Sur, México, 2000 , p. 5.
} 
haciendo inteligible su pensamiento a cualquier lector que posea un mínimo de cultura. Zilli Mánica dedicó su vida entera a la enseñanza universitaria, a la divulgación de la filosofía y a la investigación de los italianos en México. Sus libros sobre este último asunto son los clásicos, y todos los investigadores que se refieren a la migración italiana deben de una u otra forma citar la vastísima obra de Zilli. Además de todo esto, no hay que olvidar que también Zilli es un fervoroso creyente y sacerdote. Por esta razón no hay que descartar sus palabras cuando dice “¿De veras piensas que sin la revelación de Dios y su ayuda, o su gracia, el hombre puede interpretar el sentido del universo y hallar la salvación? Eso es precisamente lo que pienso"16. En este ámbito la filosofía termina su andar, aunque ciertamente apunta hacia él.

Por último, quisiéramos ahora brevemente referir — con la sinceridad y el tacto que merece-, que José Benigno Zilli pasó por una experiencia de vida de la cual en muy pocas ocasiones los humanos pueden sustraerse, a saber, la dimensión del sufrimiento y dolor por la enfermedad. De sufrimiento en cuanto desgarramiento frente a la finitud de la vida; de dolor en cuanto participe de diversas enfermedades que, lejos de amargarle la existencia, le colmaron de serenidad y virtud. No es fácil el camino que le formó en la virtud, pero él supo vivir de una manera sencilla, pues, aunque dolorosa y tortuosa, Zilli vislumbró en medio de estas vicisitudes la alegría de existir y de poner sus últimos años en pos de servir a la humanidad hasta donde le permitieran sus fuerzas. En efecto, no fue sencillo enfrentar operaciones, tratamientos y achaques propios de la debilidad que deja la edad. Sin embargo, logró transmutar estos acontecimientos en corolarios de una vida plena. Alcanzó con ahínco y disciplina superar la tristeza que conlleva el descubrir en carne propia la finitud humana. Ya decía Michel de la Montaigne haciendo eco de Platón: "filosofar es aprender a morir"; de este modo, Benigno Zilli se dispuso a combatir el día a día mostrando cómo la filosofía sirve no sólo como un modo de vivir, sino como un modo de sobrevivir a las contradicciones de la condición humana y de acercarse al ocaso. Recordaba con frecuencia que la filosofía no era ningún "cuento chino", y que había que asimilarla a la vida, sobre todo bajo la idea de caminar hacia la muerte. Como creyente no podía sentirse solitario. Con mayor sinceridad y confianza se acercó a Aquél que podía ayudarlo en la paradoja. Manifestando la condición humana en toda su plenitud, y a sabiendas que la muerte se avecinaba, se esforzó por preservar su salud, mas sin caer en

${ }^{16}$ Zilli, José Benigno, Comentarios. Acotaciones marginales, Gobierno del Estado de Veracruz-Llave, Xalapa, 1996, p. 64. 
el ensañamiento terapéutico. Mostrándose como ypóvıuos, como proporcional, la muerte le acaeció de manera sosegada, pues durmió y no despertó más a la vida terrena. Fue una dicha encontrar, después de una larga vida en la que se esforzó por ayudar a sus prójimos, la complacencia de pernoctar esperando la anhelada A $\nu \alpha \sigma \tau \alpha \sigma \iota \varsigma$. El 24 de noviembre del 2016 se durmió con la misma esperanza con la que un niño duerme en brazos de su padre; esta figura, sin romanticismos, podría perfectamente condensar todo su itinerario. Como decía el cardenal Martini (uno de sus teólogos preferidos): "Un abandono total que se nos pide también a nosotros en los momentos de oscuridad, cuando nos vemos privados progresivamente de todo apoyo humano, de toda esperanza y, poco a poco, sentimos que somos llevados con la muerte a entregarlo todo, a dejarnos llevar como niños a los brazos del padre" ${ }^{17}$ punto... Nunca se avergonzó de ser cristiano, pero sabía respetar las consciencias que no tenían el don de la fe. Él mismo decía de sí: "Era un cura, pero quería entenderlo todo y ayudó a otros en el intento. Se equivocó muchas veces, pero fue sincero en sus afanes". De esta forma, y con perseverancia ("la gracia de las gracias es la gracia de la perseverancia”, solía repetir), logró dejar una satisfacción en las distintas personas que le trataron y que pudieron comprender junto a él una escuela de vida que soporta incluso las circunstancias más difíciles.

Recibido 15 de febrero de 2018

Aceptado 2 de marzo de 2018

${ }^{17}$ Martini, Carlo Maria, Las alas de la libertad, Sal terrae, Santander, 2010, p. 15 